https://doi.org/10.30910/turkjans.753946

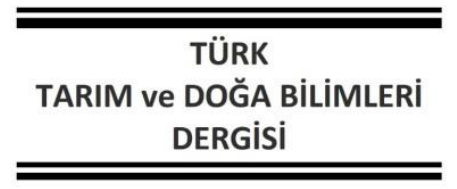

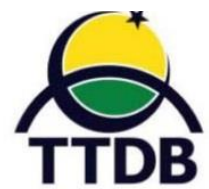

www.dergipark.gov.tr/turkjans

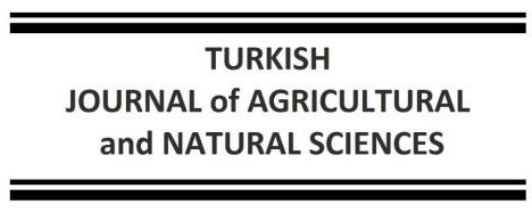

Araştırma Makalesi

\title{
Türkiye'de Yem Bitkileri Üretiminin Bölgelere Göre Karşılaştırılması
}

\author{
Ozan ÖZTÜRK \\ Atatürk Toprak Su ve Tarımsal Meteoroloji Araştırma Enstitüsü Müdürlüğü, Kırklareli \\ Sorumlu Yazar: ozan2006@gmail.com
}

\begin{abstract}
Geliş Tarihi: 17.06.2020 Düzeltme Geliş Tarihi: 29.09.2020 Kabul Tarihi: 14.10.2020
Öz

Bu çalışmanın amacı, Türkiye İstatistik Kurumu istatistiki Bölge Birimleri Sınıflaması dikkate alınarak Türkiye'deki 26 bölgenin yem bitkileri yetiştiriciliği bakımından farklıık ve benzerliklerinin ortaya konulmasıdır. Çalışmanın materyalini Türkiye İstatistik Kurumundan elde edilen ikincil veriler oluşturmuştur. Yem bitkileri ekim alanları ve üretim miktarları kullanılarak bölgeler arasındaki ilişkiler çok boyutlu ölçekleme analizi yöntemi ile ortaya konulmuştur. İzmir bölgesinin birinci boyutta en önemli ayrıştıııcı bölge olduğu, Balıkesir bölgesinin ise ikinci boyutta pozitif yükler bakımından en önemli ayrıştıııı bölge olduğu görülmekte olup bunu Erzurum bölgesi izlemektedir. Van bölgesinin birinci boyutta aldığı en yüksek negatif değerle yem bitkileri yetiştiriciliği bakımından en farkıı bölge olduğu, Konya bölgesinin ise aldığı en yüksek negatif değerle ikinci boyutta diğer bölgelerden ayrıldığı belirlenmiştir. Türkiye yem bitkileri üretimi incelendiğinde, yem bitkileri yetiştiriciliğinin belli bir sistematik içerisinde olmadığı tespit edilmiştir. Tüm tarımsal ürünlerde olduğu gibi yem bitkileri yetiştiriciliğinde de üretim planlamasının yapılması, bu planlama yapııırken bölgelerin ekolojik koşullarının yanında doğal yem kaynağı olan çayır mera varlıklarının ve ağırlıklı olarak yetiştiriciliği yapılan hayvan türlerinin de dikkate alınması gerekmektedir.
\end{abstract}

Anahtar kelimeler: Çok boyutlu ölçekleme, ekim alanı, üretim miktarı

\section{Comparison of Forage Plants Production According to the Regions in Turkey}

\begin{abstract}
The aim of this study was to reveal the differences and the similarities of the total of 26 regions of Turkey in terms of forage plants farming by considering Turkish Statistical Institute nomenclature of territorial units for statistics. The secondary data obtained from Turkish Statistical Institute composed the material of the study. The relationships between the regions were examined by multi-dimensional scaling method by using the planting areas and production amounts of the forage plants. It was determined that Izmir was the most important discriminator region in the first dimension whereas Balıkesir was the most important discriminator region in the second dimension, followed by Erzurum region. Van was the most different region in terms of forage plants farming in the first dimension with the highest negative value. Besides, it was determined that Konya differed from the other regions in the second dimension with the highest negative value. When the forage plants production in Turkey was examined, it was determined that forage plants farming was not done systematically. Production planning should be done in forage plants farming and the grass and pasture existence and the main animal kinds should be considered besides the ecological conditions.
\end{abstract}

Key words: Multi-dimensional scaling, planting area, production amount

\section{Giriş}

Tarım sektörü içerisinde en önemli konu başlıklarından birisi hayvancılıktır. Tarım işletmeleri içerisinde ekonomik olarak yılın belli bir periyoduna bağlı kalmaksızın sürekli bir gelir kaynağı olması hayvancılığı sürdürülebilir bir tarım işletmesinin olmazsa olmazı haline getirmektedir. Sürekli bir 
gelir kaynağı olan hayvancılık sektörü aynı zamanda sürekli olarak üretim maliyetleri oluşturmaktadır. Bir hayvancılık işletmesinde en önemli masraf kalemi ise yem giderleridir. Hayvancılık işletmeleri yem ihtiyacını kendi üretim alanlarından karşıladığı sürece daha karlı bir üretim yapabilmektedir. Türkiye'de hayvansal üretimde, hayvanların besin ihtiyaçları kesif yem ve kaba yem ile karşılanmaktadır. Kesif yem, yem sanayinin bir ürünü olduğu için, gerek üretim maliyetlerinin yüksek olması, gerekse fabrikadan nihai tüketiciye kadar olan aşamadaki pazarlama maliyetlerinin ürün fiyatlarına eklenmesi nedeniyle sabit olmayan fiyatlarla dalgalı bir seyir izlemektedir. Kaba yem ise genellikle doğrudan tarladan hayvanın önüne geldiği için her zaman daha ekonomik olmaktadır. Buna rağmen ülkemiz ekilebilir tarım alanlarının büyük kısmının tahıllar ve endüstri bitkileri ile ekili olması kaba yem üretimi açısından büyük bir açığın ortaya çıkmasına neden olmaktadır. Türkiye'de ekilebilir tarım alanları toplamı 23000000 hektar civarındadır. Yem bitkisi ekili alanların toplamı ise 2017 yılı itibariyle yaklaşık 2000000 hektardır Bu haliyle yem bitkisi ekili alanların tüm ekilebilir alanlar içerisindeki oranı \%9 dur. Türkiye'de en fazla ekilişi yapılan yem bitkisi; 6500000 dekarlık alanda üretimi gerçekleştirilen yoncadır. Türkiye hayvan varlığına bakıldığında, 2017 yılı rakamlarına göre 16000000 büyükbaş, 44000000 küçükbaş olmak üzere 60 milyonun üzerinde olduğu görülmektedir (TÜíK 2018). Hayvan varlığımızın Büyük Baş Hayvan Birimi (BBHB) cinsinden ifadesi $16000000 B_{B H B}$ ne tekabül etmektedir. Kuru ot cinsinden 16000000 BBHB hayvan varlığının yıllık kaba yem ihtiyacı 74000000 tondur. Yem bitkisi ekili alanlardan 2017 üretim sezonunda yaklaşık 13 000000 ton kuru ot verimi elde edilmiştir. ÇayırMeralardan elde edilen kuru ot miktarı ise 10000 000 ton civarındadır. Türkiye'de 2017 yılında üretilen toplam kuru ot miktarı 23000000 tondur. Mevcut üretimin kaba yem ihtiyacını karşılama oranı \%31 oranında olup, yaklaşık olarak 51000 000 ton kuru ot cinsinden yem açığımız bulunmaktadır. Bu kaba yem açığının kapatılması için iki seçenek vardır. Birincisi mevcut çayır-mera alanlarının genişletilmesi mümkün olmadığından bu alanların daha verimli hale getirmek adına ıslah projelerinin geliştirilmesidir. İkinci seçenek ise ekilebilir tarım alanları üzerinde münavebeye yem bitkilerinin sokulmasıdır. Gerek hayvansal üretimde kaba yem ihtiyacının karşılanmasında çok önemli bir besin kaynağı olması, gerekse toprakta bıraktıkları yüksek organik madde miktarlarıyla yem bitkileri tarla tarımında da çok önemli bir role sahiptir. Sürdürülebilir tarımsal üretim yapılabilmesi adına köklerinde bulunan rizobium bakterileri sayesinde intiyaç toprakta azot birikimi sağlayan baklagil yem bitkileri ve birim alanda toprağa bıraktıkları yoğun kök ve gövde kalıntılarıyla organik madde birikimi sağlayan buğdaygil yem bitkileri büyük önem taşımaktadır. Yem bitkileri üretiminde ciddi bir üretim planlaması yapabilmenin birinci koşulu mevcut üretim alanlarının ve miktarlarının tespit edilmesinden geçmektedir.

Bu çalışmada, Türkiye İstatistik Kurumu İstatistiki Bölge Birimleri Sınıflaması dikkate alınarak Türkiye'deki 26 bölgenin yem bitkileri ekim alanları ve üretim miktarları bakımından bölgelerin farklılık ve benzerlikleri çok boyutlu ölçekleme analizi yöntemi ile ortaya konulmuştur.

\section{Materyal ve Metot}

Çalışmanın materyalini Türkiye İstatistik Kurumundan elde edilen ikincil veriler oluşturmuş olup, Türkiye İstatistik Kurumu İstatistiki Bölge Birimleri Sınıflaması 2. düzey (26 bölge) için 2019 yılı verileri kullanılmıştır. Bu veriler, 2019 yılı için, bölgelerdeki burçak (yeşil ot), yonca (yeşil ot), korunga (yeşil ot), yulaf (yeşil ot), sorgum (yeşil ot), tritikale (yeşil ot), mürdümük (yeşil ot), mısır (hasıl), mısır (silaj), hayvan pancarı, yem şalgamı, buğday (yeşil ot), arpa (yeşil ot), çavdar (yeşil ot), bezelye (yemlik), İtalyan çimi (yemlik) ekim alanları (da) ve üretim miktarlarıdır (ton). Elde edilen veriler bakımından bölgelerin benzerlikleri ve farklılıkları çok boyutlu ölçekleme analizi ile belirlenmiştir. Çok değişkenli analiz yöntemleri iki veya daha fazla boyutlu tesadüfî değişkenleri tek değişkenmiş gibi hareket edip ve değişkenler arasındaki ilişkileri dikkate alarak kapsamlı sonuçlar veren istatistiksel analiz yöntemidir (Yiğit, 2007). Çok boyutlu ölçekleme yönteminin uygulanma koşulu, birim ya da nesneler arasındaki ilişkilerin tam olarak belirlenemediği durumlarda, uzaklık matrisinin elde edilmesi durumunda birim ya da nesneler arasındaki ilişkilerin gösterilmesidir (Kalaycı, 2006). Analizin genel amacı, nesnelerin yapısını, uzaklık değerlerini kullanarak ve mümkün olduğunca az boyutla orijinal şekle yakın bir biçimde ortaya koymaktır (Tatlıdil, 1996).

Çok boyutlu ölçekleme analizinde, çok boyutlu ( $p$ boyutlu) gerçek şekil ile indirgenmiş k-boyutlu uzayda kestirilen şekil arasındaki farklılığın ifadesi olan stress değeri hesaplanmaktadır. Metrik olmayan ölçekleme için stress değerinin formülü aşağıda verilmiştir (Johnson ve Wichern, 1992):

$$
\text { Stress }=\left(\frac{\sum_{i<j}\left(d_{i j}-\widehat{d}_{i j}\right)^{2}}{\sum_{i<j} d_{i j}^{2}}\right)^{1 / 2}
$$

Stress değeri çok boyutlu ölçekleme sonucunun uygunluğuna karar vermede kullanılmaktadır. Küçük stress değerleri iyi uyumu, yüksek stress değerleri kötü uyumu ifade etmektedir. Sonucun uygunluğunu yansıtan stress değerlerinin 
yorumlanması amacıyla Kruskal (1964) tarafından hazırlanan stress değerleri ve uyum durumu Çizelge 1'de verilmiştir (Wickelmaier, 2003). Çok boyutlu ölçekleme analizinin girdi verilerini ne kadar iyi temsil ettiğine ait korelasyon indeksi karesi olan $\mathrm{R}^{2}$ değerinin $\geq 0.60$ olması iyi bir uyum ölçüsüdür (Hair ve ark., 2006).

Çalışmada elde edilen verilere ALSCAL yöntemi uygulanmış olup, Öklit modeli kullanılmıştır.
ALSCAL diğer çok boyutlu ölçekleme programlarından farklı olarak S-Stress değerini minimize etmeye çalışır, bunun için kareli uzaklıkları kareli benzemezliklere uyarlar. Bunun sonucu olarak, ALSCAL'da büyük benzemezlikler küçük benzemezliklerden daha iyi temsil edilmektedir (Çelik, 2009). Analizde ele alınan bölgeler ve değişken kodları Çizelge 2'de verilmiştir.

Çizelge 1. Stress değerleri ve uyum

\begin{tabular}{ll}
\hline Stress değeri & Uyum durumu \\
\hline$>0.20$ & Yetersiz \\
$0.10-0.20$ & Orta \\
$0.05-0.10$ & İyi \\
$0.025-0.05$ & Mükemmel \\
$0.00-0.025$ & Tam \\
\hline
\end{tabular}

Çizelge 2. Bölgeler ve analizdeki değişken kodları

\begin{tabular}{|c|c|c|c|}
\hline Bölge & $\begin{array}{l}\text { Değişken } \\
\text { kodu }\end{array}$ & Bölge & $\begin{array}{l}\text { Değişken } \\
\text { kodu }\end{array}$ \\
\hline İstanbul & V1 & $\begin{array}{l}\text { Kırıkkale (Kırıkkale, Aksaray, Niğde, } \\
\text { Nevşehir, Kırşehir) }\end{array}$ & V14 \\
\hline Tekirdağ (Tekirdağ, Edirne, Kırklareli) & V2 & Kayseri (Kayseri, Sivas, Yozgat) & V15 \\
\hline Balıkesir (Balıkesir, Çanakkale) & V3 & Zonguldak (Zonguldak, Karabük, Bartın) & V16 \\
\hline İzmir & V4 & Kastamonu (Kastamonu, Çankırı, Sinop) & V17 \\
\hline Aydın (Aydın, Denizli, Muğla) & V5 & Samsun (Samsun, Tokat, Çorum, Amasya) & V18 \\
\hline $\begin{array}{l}\text { Manisa (Manisa, Afyon, Kütahya, } \\
\text { Uşak) }\end{array}$ & V6 & $\begin{array}{l}\text { Trabzon (Trabzon, Ordu, Giresun, Rize, } \\
\text { Artvin, Gümüşhane) }\end{array}$ & V19 \\
\hline Bursa (Bursa, Eskişehir, Bilecik) & V7 & Erzurum (Erzurum, Erzincan, Bayburt) & V20 \\
\hline $\begin{array}{l}\text { Kocaeli (Kocaeli, Sakarya, Düzce, } \\
\text { Bolu, Yalova) }\end{array}$ & V8 & Ağrı (Ağrı, Kars, Iğdır, Ardahan) & V21 \\
\hline Ankara & V9 & Malatya (Malatya, Elazığ, Bingöl, Tunceli) & V22 \\
\hline Konya (Konya, Karaman) & V10 & Van (Van, Muş, Bitlis, Hakkâri) & V23 \\
\hline Antalya (Antalya, Isparta, Burdur) & V11 & Gaziantep (Gaziantep, Adıyaman, Kilis) & V24 \\
\hline Adana (Adana, Mersin) & V12 & Şanlıurfa (Şanlıurfa, Diyarbakır) & V25 \\
\hline Hatay (Hatay, Maraş, Osmaniye) & V13 & Mardin (Mardin, Batman, Şırnak, Siirt) & V26 \\
\hline
\end{tabular}

\section{Bulgular ve Tartışma}

Çok boyutlu ölçekleme analizinde yem bitkileri üretimi açısından 26 bölgenin çok boyutlu uzaydaki konumları iki boyutlu uzayda gösterilmiştir. Stress istatistiği sonuçları Çizelge 3'te verilmiştir. Değişkenlere göre uzaklık matrisinin hesaplandığı analizde 3 iterasyon gerçekleşmiştir. Stress istatistiği 0.18150 ve uyumluluk seviyesi "orta" olarak bulunmuştur. Analizde açıklayıcılık katsayısı olan $\mathrm{R}^{2} \quad 0.87667$ olarak bulunmuştur. Bu değerin yüksek çıkması (\%60'ın üzerinde olması) beklenir. $k=2$ boyut için stres değerinin verileri \%87.667 oranında açıkladığı anlamına gelmektedir. 
Çizelge 3. İterasyon geçmişi

\begin{tabular}{ccc}
\hline Iterasyon & S-stress değeri & Gelişme \\
\hline 1 & 0.19928 & - \\
2 & 0.17353 & 0.02576 \\
3 & 0.17294 & 0.00058 \\
\hline Stress ístatistiği & & 0.18150 \\
\hline RSQ & 0.87667 & \\
\hline
\end{tabular}

Bölgelerin iki boyutlu koordinat değerleri Çizelge 4'te verilmiştir. Birinci boyutta Tekirdağ, Balıkesir, İzmir, Aydın ve Şanlıurfa bölgeleri yem bitkileri üretimi bakımından en önemli bölgeler olduğu belirlenmiştir. Bu bölgelerin 1'in üzerindeki pozitif değerlerle en büyük etkiye sahip olduğu sonucuna ulaşılmıştır. İzmir bölgesi ise 2'nin üzerinde pozitif değer almıştır ve bu boyuttaki en önemli bölge konumundadır. Tekirdağ bölgesinde silajlık mısır ekimi yoğun olup, yemlik bezelye üretiminde Türkiye'de ikinci sırada bulunmaktadır. Bunun yanında, buğday (yeşil ot), çavdar (yeşil ot) ve Italyan çimi üretimi de bölgede yaygın olarak yapılmaktadır. Balıkesir bölgesi ise yulaf (yeşil ot), sorgum, buğday (yeşil ot), çavdar (yeşil ot) ve İtalyan çimi üretiminde Türkiye'de birinci sırada yer almaktadır. Bu bölgede ayrıca tritikale, silajlık mısır, hayvan pancarı, yem şalgamı, arpa (yeşil ot) yetiştiriciliği de yaygın olarak yapılmaktadır. İzmir bölgesi ise yem şalgamı yetiştiriciliği bakımından Türkiye'de ilk sırada olup, diğer bölgelerin çoğundan belirgin bir şekilde ayrılmaktadır. İzmir bölgesinde ayrıca silajlık mısır ve tritikale üretimi de yaygın olarak yapılmaktadır. Aydın bölgesinde ele alınan tüm yem bitkilerinin ekimi gerçekleştirilmekte olup, arpa (yeşil ot) üretiminin hemen hemen yarısı bu bölgede yapılmaktadır. Bu bölge ayrıca tritikale, mısır (hasıl) ve silajlık mısır üretimi bakımından Türkiye'de birinci sırada yer almaktadır. Türkiye'de yaygın olarak üretimi yapılmayan mürdümük yetiştiriciliği bakımından bu bölge üçüncü sırada yer almaktadır. Şanlıurfa bölgesinde ise burçak bitkisi ve yemlik bezelye üretimi diğer bölgelerle kıyaslandığında ortalamanın üzerinde yer almaktadır. Bu bölgede ayrıca silajlık mısır ve yonca üretimi de yoğun olarak yapılmaktadır. Birinci boyutta analize dâhil edilen bölgeler içinde Kayseri, Erzurum, Ağrı, Malatya ve Van bölgelerinin negatif yüklü olduğu görülmektedir. Bu bölgelerden Kayseri ve Malatya bölgeleri 1'in, Erzurum ve Ağrı bölgeleri 2'nin, Van bölgesi ise 3'ün üzerinde negatif değerlere sahip olup, bu bölgeler birincil derecede önemli değildir. $\mathrm{Bu}$ durum, bu bölgelerin yem bitkileri üretimi bakımından diğer bölgelerden farklı olduklarını göstermektedir. Kayseri bölgesinde yem bitkileri yetiştiriciliği ağırlıklı olarak yonca, korunga, yulaf ve silajlık mısır üretiminde dayalıdır. Malatya Bölgesinde Türkiye'de birçok bölgede üretimi yapılmayan mürdümük bitkisi üretimi Malatya Bölgesinde diğer bölgelere göre oldukça yüksektir. Türkiye mürdümük üretiminin hemen hemen yarısı bu bölgede yapılmaktadır. Erzurum ve Ağrı bölgelerinde ise yonca, korunga, yulaf üretimi oldukça öne çıkmaktadır. Özellikle Van bölgesi 3'ün üzerinde negatif değerle 26 bölge içinde en farklı bölge konumundadır. Van bölgesinde yonca üretimi diğer bölgelere oranla oldukça fazla olup, kendisine en yakın bölge olan Ağrı bölgesindeki yonca ekim alanının iki katından fazla ekim alanına ve sahiptir. Bu bölgede ayrıca korunga yetiştiriciliği de oldukça fazla olup diğer yem bitkilerinin üretimi yapılmamaktadır. Yem bitkileri içinde oldukça önemli bir yer tutan ve birçok bölgede yaygın olarak yetiştirilen silajlık mısır üretiminin Erzurum, Malatya, Ağrı ve Van bölgelerinde çok yaygın olmadığı görülmüştür. Yem bitkileri üretimi bakımından Erzurum, Malatya, Ağrı ve Van bölgelerinin birbirine benzer yapıda olduğu belirlenmiştir. İkinci boyutta ise Balıkesir ve Erzurum bölgelerinin hem pozitif hem de 1'in üzerinde değerler almaları nedeniyle yem bitkileri üretimi bakımından en önemli ayrıştırıcı bölgeler olduğu ortaya çıkmaktadır. Balıkesir bölgesinde ele alınan yem bitkilerinin tamamı yetiştirilmektedir. $\mathrm{Bu}$ yüzden bu bölge hem birinci boyutta hem de ikinci boyutta 1 'in üzerinde pozitif değer alarak diğer bölgelerden yem bitkileri yetiştiriciliği bakımından ayrılarak en önemli bölge konumunda yer almıştır. Erzurum Bölgesinde yemlik bezelye üretimi, Malatya ve Ağrı bölgeleriyle karşılaştırıldığında oldukça yüksektir. Korunga (yeşil ot) ekim alanı Van ve Ağrı bölgelerinden düşük iken, elde edilen üretim miktarı ise bu bölgelere oranla oldukça yüksektir. Yulaf ekim alanı ise Ağrı bölgesindeki ekim alanından düşük ancak üretim miktarı yüksektir. Tritikale üretimi bakımından değerlendirildiğinde ise, ekim alanı olarak Ağrı bölgesinde tritikale ekim alanından yaklaşık olarak 1.5 kat fazla iken elde edilen üretim miktarı Ağrı 
bölgesinden elde edilen üretim miktarından yaklaşık olarak 10 kat daha fazladır. Konya ve Kırıkkale bölgelerinin ikinci boyutta 1 'in üzerinde negatif değerlere sahip olduğu görülmektedir. Konya bölgesinde burçak yetiştiriciliği diğer bölgelerden farklılık göstermektedir. Ayrıca bu bölgede, birinci boyutta 1'in üzerinde pozitif değer alan Tekirdağ, Balıkesir, İzmir ve Aydın bölgelerinin aksine arpa (yeşil ot) üretimi yapılmamaktadır. Kırıkkale bölgesinde ise çavdar (yeşil ot), buğday (yeşil ot), arpa (yeşil ot) ve İtalya çimi üretimi birinci boyutta 1'in üzerinde pozitif değerler alan Balıkesir ve Aydın bölgelerinin tersine oldukça düşük miktarlarda yapılmaktadır. Her iki boyut göz önüne alındığında, Tekirdağ, Balıkesir, Manisa, Bursa, Kocaeli, Antalya, Zonguldak ve Samsun bölgeleri her iki boyutta pozitif yüklere sahiptir. Kırıkkale, Trabzon, Malatya, Van ve Mardin bölgelerinin ise her iki boyutta negatif işaretli olduğu ve bu nedenle bu bölgelerin yem bitkileri üretimi bakımından en zayıf bölgeler olduğunu söylemek mümkündür.

Çizelge 4. Bölgeler için hesaplanan koordinatlar

\begin{tabular}{|c|c|c|c|c|c|}
\hline Regions & Dimension 1 & Dimension 2 & Regions & Dimension 1 & Dimension 2 \\
\hline İstanbul (V1) & -0.1726 & 0.5623 & Kırıkkale (V14) & -0.5160 & -1.3043 \\
\hline Tekirdağ (V2) & 1.1072 & 0.0690 & Kayseri (V15) & -1.0942 & 0.4722 \\
\hline Balıkesir (V3) & 1.5808 & 1.4529 & Zonguldak (V16) & 0.0232 & 0.5332 \\
\hline İzmir (V4) & 2.0954 & -0.4698 & Kastamonu (V17) & -0.4677 & 0.6364 \\
\hline Aydın (V5) & 1.2491 & -0.7853 & Samsun (V18) & 0.4994 & 0.0277 \\
\hline Manisa (V6) & 0.3830 & 0.5061 & Trabzon (V19) & -0.7382 & -0.0224 \\
\hline Bursa (V7) & 0.6954 & 0.2464 & Erzurum (V20) & -2.2098 & 1.0561 \\
\hline Kocaeli (V8) & 0.9998 & 0.3626 & Ağrı (V21) & -2.3482 & 0.3427 \\
\hline Ankara (V9) & 0.1984 & -0.0746 & Malatya (V22) & -1.1267 & -0.5277 \\
\hline Konya (V10) & 0.3799 & -1.6811 & Van (V23) & -3.3139 & -0.8223 \\
\hline Antalya (V11) & 0.6864 & 0.6474 & Gaziantep (V24) & 0.8085 & -0.2488 \\
\hline Adana (V12) & 0.3435 & -0.1143 & Şanlıurfa (V25) & 1.1151 & -0.4753 \\
\hline Hatay (V13) & 0.4971 & -0.2923 & Mardin (V26) & -0.6748 & -0.0967 \\
\hline
\end{tabular}

Çalışmada yem bitkileri ekim alanları açısından bölgelerin benzerlik ve farklılıklarını gösteren harita Şekil 1'de verilmiştir. Bölgeler arasındaki uzaklıklar arttıkça ele alınan değişkenler açısından farklııkların arttığı, uzaklıklar azaldıkça benzerliklerin arttığı görülmektedir. Şekil 1 incelendiğinde, Balıkesir, İzmir, Konya, Kırıkkale, Erzurum, Ağrı ve Van bölgelerinin diğer bölgelere göre farklı olduğu belirlenmiştir. 


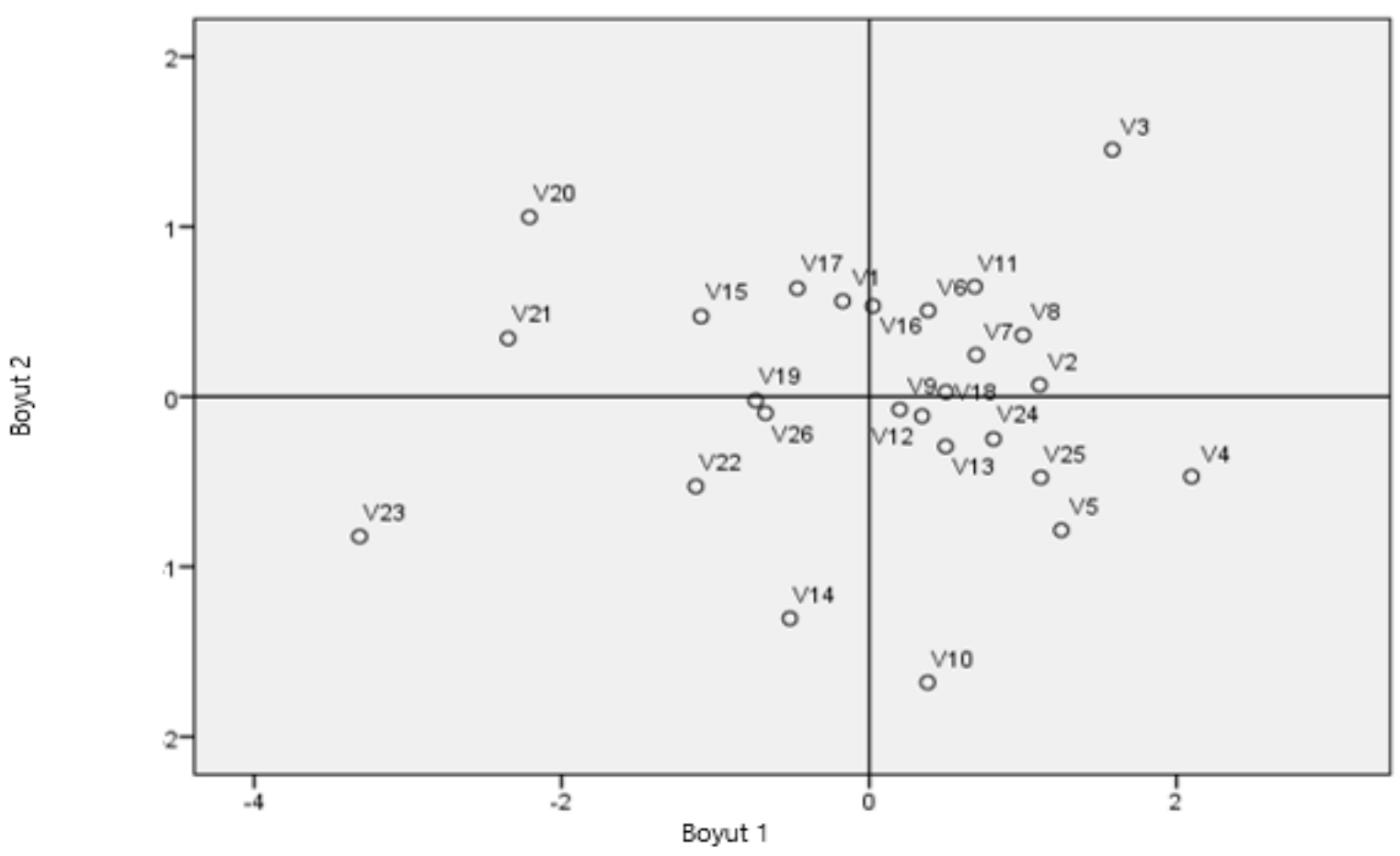

Şekil 1. Bölgelerin iki boyutlu uzayda gösterimi

Tarımda çok boyutlu ölçeklemenin değişik alanlarda kullanımı konusunda bazı çalışmalar bulunmakla beraber, yem bitkileri yetiştiriciliği bakımından bölgeler arası karşılaştırma yapılmış olan bir çalışmaya rastlanmamıştır. Doğan (2003) tarafından yürütülen çalışmada kuzularda büyüme çok boyutlu ölçekleme yöntemi ile belirlenmiştir. Çukur ve ark. (2010) Ege Bölgesindeki illerin tarımsal makine parklarını ve tarımsal mekanizasyon düzeylerini çok boyutlu ölçekleme analizi ile incelemişlerdir. Gevrekçi ve ark. (2011) tarafından yapılan çalışmada koyunculuk faaliyeti açısından Batı Anadolu illeri sınıflandırılmıştır. Aydın, Bursa ve Muğla illerinin Batı Anadolu koyunculuğunda en zayıf iller olduğu tespit edilmiştir. Çelik (2015) tarafından yapılan çalışmada Türkiye'deki illerin hayvancılık bakımından benzerlik ve farklılıkları belirlenmiştir. Şırnak, Antalya, Siirt ve Bitlis illerinin hayvancılık bakımından diğer illerden farklı olduğu ve Tunceli, Hakkâri, Van, Şanlıurfa, Siirt, Bitlis ve Şırnak illerinin Türkiye hayvancılığına en fazla pozitif etki yapan iller olduğu belirlenmiştir. Turgut (2016) tarafından yapılan çalışmada Orta Anadolu illerinin tarımsal yapısı belirlenmiştir. Sivas ve Konya illerinin büyükbaş hayvancılık bakımından, Konya ilinin küçükbaş hayvancılık bakımından, Konya ve Ankara illerinin kümes hayvancılığı bakımından diğer Orta Anadolu illerinden farklı bir yapıda olduğu tespit edilmiştir. Adanacıoğlu ve ark. (2017), Türkiye'deki 81 ilin tarımsal üretim değerini, tarımsal kredi hacmini ve kredi performansını birlikte değerlendirerek, illerin birbirlerine olan farklılık ve benzerliklerini çok boyutlu ölçekleme analizi ile belirlemişlerdir. Adanacıoğlu ve ark. (2018) Türkiye'deki 12 bölgenin canlı keçi, teke, keçi sütü ve eti fiyatlarını birlikte değerlendirerek bölgelerin birbirlerine olan benzerlik ve farklılıklarını ortaya koymuşlardır. İstanbul ve Batı Marmara bölgesinin sırayla birinci ve ikinci boyutta en önemli bölgeler olduğu belirlenmiştir. Aldıkları en yüksek negatif değerlerle ise canlı hayvan, et ve süt fiyatları bakımından en farklı bölgelerin birinci boyutta Kuzeydoğu Anadolu, ikinci boyutta ise Orta Anadolu bölgeleri olduğu sonucuna ulaşılmıştır.

\section{Sonuç ve Öneriler}

$\mathrm{Bu}$ çalışmada, Türkiye'de yem bitkileri üretiminin yapısı ortaya konulmuştur. Elde edilen sonuçlara göre bazı bölgelerin yem bitkileri ekim alanı ve üretim miktarı bakımından diğer bölgelerden önemli ölçüde ayrıldığı görülmüştür. İzmir bölgesi birinci boyutta pozitif yükler bakımından en önemli ayrıştırıcı bölge olarak belirlenmiştir. İkinci boyuttaki pozitif yükler bakımından değerlendirildiğinde ise, Balıkesir bölgesinin incelenen değişkenler açısından en önemli ayrıştırıcı bölge olduğu görülmekte olup bunu Erzurum bölgesi izlemektedir. Aldığı en yüksek negatif değerle yem bitkileri yetiştiriciliği bakımından en farklı bölge birinci boyutta Van bölgesi iken, ikinci boyutta ise Konya bölgesidir. Balıkesir bölgesinde ele alınan 16 yem bitkisinin tamamının üretildiği ve bu bölgenin birçok ürün açısından Türkiye'de ilk sırada yer aldığı belirlenmiştir. Van bölgesinde ise yonca 
yetiştiriciliği diğer bölgelere göre oldukça yüksek olup, birçok yem bitkisinin bu bölgede yetiştirilmediği görülmüştür. Bölgeler özelinde Türkiye yem bitkileri üretimi incelendiğinde, yem bitkileri yetiştiriciliğinin belli bir sistematik içerisinde olmadığı tespit edilmiştir. Tüm tarımsal ürünlerde olduğu gibi yem bitkileri yetiştiriciliğinde de üretim planlamasının yapılması, bu planlama yapılırken bölgelerin ekolojik koşullarının yanında doğal yem kaynağı olan çayır mera varlıklarının ve ağırlıklı olarak yetiştiriciliği yapılan hayvan türlerinin de dikkate alınması gerekmektedir.

Çıkar Çatışması Beyanı: Makale yazarları aralarında herhangi bir çıkar çatışması olmadığını beyan ederler.

\section{Araştırmacıların Katkı Oranı Beyan Özeti:}

Yazarlar makaleye eşit oranda katkı sağlamış olduklarını beyan ederler.

\section{Kaynaklar}

Adanacıoğlu, H., Artukoğlu, M., Güneş, E. 2017. Türkiye'de tarımsal kredi performansının çok boyutlu ölçekleme yaklaşımıyla analizi. Tarım Ekonomisi Dergisi, 23(2): 195-204.

Adanacıoğlu, H., Taşkın, T., Kandemir, Ç., Koşum, N. 2018. Türkiye'de keçi yetiştiriciliği ekonomisinin bölgelere göre çok boyutlu ölçekleme analizi ile karşılaştırılması. Ege Üniv. Ziraat Fak. Derg., 55(3): 245-253.

Çelik, S. 2009. Çağrı merkezlerinde performans değerlendirme. İstanbul Üniversitesi Sosyal Bilimler Enstitüsü, Yüksek Lisans Tezi, İstanbul.

Çelik, Ş. 2015. Çok boyutlu ölçekleme analizi ile hayvancılık açısından Türkiye'de illerin sınıflandırılması. Erciyes Üniversitesi Fen Bilimleri Enstitüsü Dergisi. 31(4): 1-6.

Çukur, T., Saner, G., Güler, H. 2010. Türkiye'de tarımsal mekanizasyon düzeyi ve tarım makineleri parkının çok boyutlu ölçekleme analizi ile incelenmesi: Ege Bölgesi örneği. Adnan Menderes Üniversitesi Ziraat Fakültesi Dergisi, 7(2): 33-40.

Doğan, í. 2003. Kuzularda büyümenin çok boyutlu ölçekleme yöntemi ile değerlendirilmesi. Uludağ Üniversitesi Veterinerlik Fakültesi Dergisi. 22(1-2-3): 33-37.

Gevrekçi, Y., Ataç, F.E., Takma, Ç., Akbaş, Y., Taşkın, T. 2011. Koyunculuk açısından Batı Anadolu illerinin sınıflandırılması. Kafkas Üniversitesi Veteriner Fakültesi Dergisi, 17(5): 755-760.

Hair, J.F., Anderson, R.E., Black, W.C., Tatham, R.L. 2006. Multivariate Data Analysis: With Readings. Mcmillan Book Company, London.

Johnson, R., Wichern, D. 1992. Applied Multivariate Statistical Analysis (3th ed.). Prentice Hall, USA.

Kruskal, J.B. 1964. Nonmetric multidimensional scaling: a numerical method. Psychometrika, 29:115-129.

Kalaycı, Ş. 2006. SPSS Uygulamalı Çok Değişkenli İstatistik Teknikleri, Asil Yayınevi, 2006, s.379.

Tatlıdil, H. 1996. Uygulamalı Çok Değişkenli İstatistiksel Analiz, Ankara.

Turgut, Ö. 2016. Orta Anadolu illerinin tarımsal yapısının çok boyutlu ölçekleme ve kümeleme analizleri ile belirlenmesi. Ahi Evran Üniversitesi Fen Bilimleri Enstitüsü, Yüksek Lisans Tezi, Kırşehir.

TÜiK, 2018. İstatistik Göstergeler. http://www.tuik.gov.tr.

Wickelmaier, F. 2003. An introduction to MDS. Reports from the Sound Quality Research Unit).

Yiğit, E. 2007. Çok boyutlu ölçekleme yöntemlerinin incelenmesi ve bir uygulama. Ondokuz Mayıs Üniversitesi Fen Bilimleri Enstitüsü, Yüksek Lisans Tezi, Samsun. 